\title{
Materialist and Post-Materialist Concerns and the Wish for a Strong Leader in 27 Countries
}

\author{
Marcus E. O. Lima ${ }^{1}$, Dalila X. de França ${ }^{1}$, Jolanda Jetten ${ }^{2}$, Cícero R. Pereira ${ }^{3}$, Michael J. A. Wohl ${ }^{4}$, Inga Jasinskaja-Lahti ${ }^{5}$, \\ Ying-yi Hong ${ }^{6}$, Ana Raquel Torres ${ }^{3}$, Rui Costa-Lopes ${ }^{7}$, Amarina Ariyanto $^{8}$, Frédérique Autin ${ }^{9}$, Nadia Ayub $^{10}$, \\ Constantina Badea ${ }^{11}$, Tomasz Besta ${ }^{12}$, Fabrizio Butera ${ }^{9}$, Carole Fantini-Hauwel ${ }^{13}$, Gillian Finchilescu ${ }^{14}$, Lowell Gaertner ${ }^{15}$, \\ Mario Gollwitzer ${ }^{16}$, Ángel Gómez ${ }^{17}$, Roberto González ${ }^{18}$, Dorthe Høj Jensen ${ }^{19}$, Minoru Karasawa ${ }^{20}$, Thomas Kessler ${ }^{21}$, \\ Olivier Klein ${ }^{22}$, Laura Megevand ${ }^{23}$, Thomas Morton ${ }^{24}$, Maria Paola Paladino ${ }^{25}$, Tibor Polya ${ }^{26}$, Tuuli Anna Renvik ${ }^{5}$, \\ Aleksejs Ruza ${ }^{27}$, Wan Shahrazad ${ }^{28}$, Sushama Shama ${ }^{29}$, Heather J. Smith ${ }^{30}$, Ali Teymoori ${ }^{31}$, Anne Marthe van der Bles ${ }^{32}$ \\ [1] Federal University of Sergipe, Sergipe, Brazil. [2] University of Queensland, Brisbane, Australia. [3] Federal University of Paraíba, João Pessoa, Brazil. \\ [4] Carleton University, Ottawa, ON, Canada. [5] University of Helsinki, Helsinki, Finland. [6] Chinese University of Hong Kong, Hong Kong. [7] University of \\ Lisbon, Lisbon, Portugal. [8] University of Indonesia, Jakarta, Indonesia. [9] University of Lausanne, Lausanne, Switzerland. [10] Institute of Business \\ Management, Karachi, Pakistan. [11] Université Paris Nanterre, Paris, France. [12] University of Gdańsk, Gdańsk, Poland. [13] Research Center for Experimental, \\ Clinical \& Cognitive Psychopathology (MEANING), ULB, Brussels, Belgium. [14] University of the Witwatersrand, fohannesburg, South Africa. [15] University of \\ Tennessee, Knoxville, TN, USA. [16] Philipps University, Marburg, Germany. [17] Universidad Nacional de Educación a Distancia, UNED, Madrid, Spain. \\ [18] Pontificia Universidad Católica de Chile, Santiago, Chile. [19] Aarhus University, Aarhus, Denmark. [20] Nagoya University, Nagoya, fapan. [21] University \\ of Jena, Jena, Germany. [22] Université Libre de Bruxelles, Brussels, Belgium. [23] ISCTE-University Institute of Lisbon, Lisbon, Portugal. [24] University of \\ Copenhagen, Copenhagen, Denmark. [25] University of Trento, Trento, Italy. [26] Hungarian Academy of Sciences, Budapest, Hungary. [27] Daugavpils \\ University, Daugavpils, Latvia. [28] National University of Malaysia, Bangi, Malaysia. [29] Kurukshetra University, Kurukshetra, India. [30] Sonoma State \\ University, Rohnert Park, CA, USA. [31] Helmut Schmidt University, Hamburg, Germany. [32] University of Groningen, Groningen, Netherlands.
}

Journal of Social and Political Psychology, 2021, Vol. 9(1), 207-220, https://doi.org/10.5964/jspp.6213

Received: 2020-03-23 • Accepted: 2021-01-28 • Published (VoR): 2021-05-10

Handling Editor: Jasper van Assche, Ghent University, Ghent, Belgium

Corresponding Author: Marcus E. O. Lima, Federal University of Sergipe, Cidade Univ. Prof. José Aloísio de Campos, Av. Marechal Rondon, s/n, Jd. Rosa Elze, São Cristóvão/Se CEP 49100-000, Brazil. E-mail: marcus@academico.ufs.br

Supplementary Materials: Materials [see Index of Supplementary Materials]

\section{Abstract}

There is evidence that democracies are under threat around the world while the quest for strong leaders is increasing. Although the causes of these developments are complex and multifaceted, here we focus on one factor: the extent to which citizens express materialist and post-materialist concerns. We explore whether objective higher levels of democracy are differentially associated with materialist and post-materialist concerns and, in turn, whether this is related to the wish for a strong leader. Testing this hypothesis across 27 countries $(\mathrm{N}=5,741)$ demonstrated a direct negative effect of democracies' development on the wish for a strong leader. Further, multi-level mediation analysis showed that the relation between the Democracy Index and the wish for a strong leader was mediated by materialist concerns. This pattern of results suggests that lower levels of democracy are associated with enhanced concerns about basic needs and this is linked to greater support for strong leaders.

\section{Keywords}

materialist concerns, post-materialist concerns, leadership, democracy, populism 
The above quote reminds us that we only consider our spiritual aspirations after we have satisfied our more urgent needs. Is this statement also appropriate for understanding political setbacks in terms of democracy's stagnation and even decline in some countries in the world? That is, is there a relation between the extent to which the erosion of democracy and concerns that basic materialist needs are not met? Here, we propose that in struggling democracies, the extent to which basic security and material welfare needs of citizens are compromised may be associated with a greater wish for a strong leader who might be willing to improve material conditions even if this is achieved by non-democratic means. In this paper, we focus on one particular setback this development may be associated with: the quest for a strong leader. Even though a strong leader may hold the promise to fix problems, the election of such a leader has also been found to further erode democracy, threatening citizens' civil and political liberties (see Crouch, 2019; Sprong et al., 2019). We explored the relation between democratic development and the wish for a strong leader in 27 countries. Specifically, we assessed whether the quest for a strong leader in contexts that experience low democracy may be explained by concerns about materialist versus post-materialist need satisfaction.

\section{Threats to Democracy}

In recent times, we have witnessed a decline in or stagnation of democracy and a surge of authoritarianism and populism throughout the world. The Democracy Index, created by The Economist Intelligence Unit (EIU), provides an overview of the current state of democracies. From 2006 to 2014, data from 165 countries and two territories, indicate that 48 countries/territories improved the strength of their democracy, 71 remained constant, and 48 experienced a decline in democracy. Democracies eroded in Latin America, the Middle East and Africa. In Asia and Eastern Europe, there was little improvement in the Democracy Index. Interestingly too, in the US and Western Europe, there was a decline in democracy that was accompanied by the growth of populist parties (EIU, 2014). However, in 2015 and 2018, the democracy score stagnated, and in 2016 and 2019, it declined. The average global score for democracy of 167 countries covered by the Index fell in 2019 to 5.44, reaching the worst result since the index was created in 2006. Democracy index declines happened in Latin America and Sub-Saharan Africa, and to a lesser extent in the Middle East and North Africa. The other global areas covered by the Democracy Index show stagnation (EIU, 2019).

Similarly, Freedom House data from 193 countries showed that even though 94 countries could be classified as "Free democracies" in 2005 , the democracy ranking of 21 countries $(22 \%)$ had declined and only six countries (6\%) had become more democratic in 2016. Among the 60 nations classified as having "hybrid regimes", 29 (48\%) presented democratic retrogression and only 10 countries $(17 \%)$ had become more democratic in that time. Finally, of the 39 "autocracies", 12 (31\%) had declined even more in terms of their strength of democracy and $13(33 \%)$ had advanced toward democracy (Norris, 2017a). Importantly too, there is evidence that attitudes towards the importance of democracy have become more negative. Many, including younger generations, have adopted a deeply cynical view of the importance of defending democracy (Norris, 2017b). Political cynicism has been found to be predictive of right-populist party support in some Western countries (Van Assche et al., 2018).

There are indications that the corrosion of democracy goes hand in hand with the rise of authoritarian and populist leaders (Inglehart, 2018; Inglehart \& Welzel, 2012). It has been argued that the appeal of strong or populist leaders results from the weakening of pro-democratic beliefs, the erosion of faith in democracy and the willingness of politicians to "follow the rules of the game" (Daly, 2018). This may be true even in wealthy and post-industrialized countries that have stable democracies, such as France, Denmark, The Netherlands, Austria, and more recently the United States and the UK (Inglehart \& Norris, 2017).

\section{Concerns About Materialist and Post-Materialist Needs}

Here, we focus on the decline in democracy worldwide and ask whether this decline is related to growing support for strong leaders. In exploring this, we argue there is a key role for the extent to which materialist concerns are

1) Translated in English as Food first, then morality. 
satisfied in a country. According to some, concerns or values play a fundamental role in people's cognitive, emotional and social functioning (Cooper \& Denner, 1998; Sortheix \& Schwartz, 2017). In this, values are conceptualized as the bridge that connects individuals to culture. There is ample evidence that two axiological dimensions are fundamental in connecting individuals to their political culture: materialist and post-materialist values (Inglehart, 1971, 2008; Inglehart \& Welzel, 2005). Specifically, Inglehart (1971) developed theorizing on how values changed over time and he noted that a "silent revolution" was occurring in Europe in the 1970s. This involved an intergenerational shift in values, whereby the younger generation of the most industrialized countries were moving away from prioritizing "materialist" objectivesvalues or objectives that are immediately linked with survival, such as economic and physical security. Instead, they were increasingly pursuing post-materialist objectives linked to values such as expression, freedom, privacy and quality of life.

Inglehart (1971) understood values as forming a framework for social priorities and argued that in more post-materialist societies, economic welfare plays an important role in legitimizing democratic institutions, so that when people are dissatisfied with policies, they elect new leaders. In more materialist societies, when basic living conditions are not guaranteed, citizens may reject the democratic form of government and look for strong and authoritarian leaders instead (Inglehart, 2000). Only when people live in economic and physical security, may successive generations focus less on survival needs and more on intangibles or post-materialist values, such as liberties and self-expression-values at the heart of a vibrant democracy (Inglehart, 2018).

The reasoning concerning materialist and post-materialist values has made a substantial contribution to understanding how economic fluctuations produce changes in political attitudes (Kaase \& Newton, 1995). The methodological approach that is typically used to test key predictions is quite intuitive. Surveys generally ask citizens about the most important objectives in their country, presenting a list with four options: two materialist (maintaining order and fighting rising prices); and two post-materialist (protecting freedom of speech and giving people more say). Participants are asked to rank these values in order of importance to them (Inglehart \& Abramson, 1999). Using data from the World Values Survey from 65 countries in the period from 1981 to 1998, Inglehart and Baker (2000) found that adherence to post-materialist values guides more rationalist and secular spiritual tenets, and this is more common in post-industrial societies with high levels of economic security. Indeed, this axis was associated with tolerance, subjective well-being, democratic political activism and self-expression. However, in developing countries, people tended to place more emphasis on materialist values and traditional spiritual orientations, putting economic and physical security above all other goals. This axis was linked to the perception that foreigners pose a threat, the rejection of ethnic diversity and cultural change, intolerance of social minorities and more authoritarian political views (Inglehart \& Baker, 2000). In accordance with Inglehart and Welzel (2012), we argue that higher GDP alone does not produce democracy, but allows the emergence of a post-industrial society whose cultural changes lead to democratization. In this sense, it is not surprising that, materialist values, and not so much post-materialist values, have been found to predict support for non-democratic and authoritarian political alternatives (Inglehart, 2000).

For the last two decades, the world can be said to have been living in the "After Post-materialism" era, with many countries suffering from declining per capita income levels. Therefore, although Inglehart (1971) focused on a shift from materialism to post-materialism, at present, as a result of economic decline, the world is arguably facing a period where post-materialist values are replaced by materialist values. At the same time, we have entered a period of democratic decay unparalleled since the Nazi-Fascism of the 1930s. As outlined, in recent years, many countries with incipient democratic systems have slid back into dictatorship, and others, with more consolidated democratic institutions, adhere to authoritarian populism (Inglehart, 2018; Inglehart \& Welzel, 2012).

Interestingly, it is clear that the democracy decay has also coincided with the decline in the embrace of post-materialist values, and values have been found to be subject to change. For example, the trend toward post-materialism in the 1970s was inhibited by various economic adversities, especially in the 1980s, stimulating a return of materialist worries even in many post-industrial countries of Europe (Abramson \& Inglehart, 1987). And, more recently, since 2007 or 2008, reflecting widespread global economic recession, materialist values have become more important again. This development has been described as a backlash against the "Silent Revolution" (Inglehart \& Norris, 2017).

To understand the link between post-materialist and materialist values and support for a strong leader, a related phenomenon must be considered. In contexts of economic growth, tolerance and democracy are more able to flourish 
than in contexts where countries' GDP per capita is lagging because that produces job insecurity and a decline of real income (Hadler, 2012). In this scenario, a "materialist reaction" against cultural changes could arise, nourishing support for conservative parties and "strong leaders" who promise to bring back the "good times" (Sprong et al., 2019). In that sense, we agree that "postmaterialism eventually became its own gravedigger" (Inglehart \& Norris, 2017, p. 444). In our research, we explore the separate and unique influence of economic performance (as measured by country level Gross Domestic Product, GDP per capita) on the wish for a strong leader, and also control for this variable in our analyses of the influence of (post)materialist concerns.

\section{Overview of the Current Study}

We analyzed the relation between the democracy index and the wish for a strong leader in 27 countries. We explored the relationship between democratic development (as assessed by the Democracy Index) and the wish for a strong leader and examined whether materialist and/or post-materialist concerns mediated this relation.

We measured materialist and post-materialist concerns in a slightly different way than Inglehart (2008), focusing on the extent to which participants are concerned about their country's problems relating to materialist and post-materialist values. In Inglehart's theory, values represent aspects of the desirable that guide the preferences of individuals and groups. In our research, we ask not for "desirable", but for what guides, as an interest, norm or a necessity, the day-to-day living of citizens in each country. We hypothesized that our strategy may overcome several shortcomings of the original measurement. First, as stated by Davis and Davenport (1999) in a criticism of Inglehart's methodology, the ranking strategy used in their studies makes it difficult to perform factor analysis, since the items are not independent. As such, we used a ratio scale instead ${ }^{2}$.

Second, Inglehart's classic studies included only four items to assess two dimensions (see Inglehart \& Abramson, 1999), which asked participants to choose two of these items that they considered most important to them personally. We presented a broader list of topics of concern, including environmental issues and the perceived quality of social services. Third, to better capture societal perceptions, we asked participants to consider how an average citizen of their country would respond. Even though this may reflect personal views, by asking about ordinary citizens' everyday concerns with their country, we move the focus to collectively shared perceptions. Finally, although Inglehart understands values as concerns about forms of existence (Inglehart \& Baker, 2000; Inglehart \& Welzel, 2005), in their studies, they ask participants to respond to items that only reflect their values. However, asking participants to report about their own concerns instead allows participants to provide more direct answers about negative elements of countries' socio-political agenda, such as corruption, unemployment, crime and selfishness or egotism. As such, we assessed participants' concerns in the current study.

In line with Inglehart and collaborators (Inglehart, 2000, 2008, 2016; Inglehart \& Norris, 2017; Inglehart \& Welzel, 2005), we hypothesized that lower levels of democracy would be associated with greater support for a strong leader and that materialist concerns would mediate this relationship. We were open to the finding that post-materialist concerns would also mediate this relationship and we explored this possibility. Furthermore, we explored the difference in materialist versus post-materialist concerns and examined whether lower concerns relating to post-materialist values relative to materialist values would be associated with a wish for strong leaders; those who promise to overcome societies' difficulties by ensuring first and foremost that the basic material conditions needed for existence are met (Inglehart \& Norris, 2016).

2) The problem with the rating method is that it can generate classifications in which respondents place great importance on all items (Inglehart \& Abramson, 1999). That is why Inglehart's methodological approach forces opposition between materialism and post-materialism values. 


\section{Method}

\section{Participants}

The data collection process started in January 2014 and ended in February 2015. ${ }^{3}$ Participants were recruited from 30 universities in Asia (China, Japan, Malaysia, Singapore, Indonesia, India, Pakistan), the Middle East (Iran), Africa (South Africa), Oceania (Australia), North America (Canada, and the US - one dataset from Tennessee and one from Northern California), South America (Chile and Brazil), and Europe (Netherlands, UK, Spain, Italy, France, Denmark, Finland, Switzerland, Belgium, Portugal, Poland, Hungary, Latvia and Germany - one dataset from former East Germany and one from former West Germany). The original version of the questionnaire was translated into the respective native languages of the countries. The participants completed the survey via an online platform or a hard copy.

We dropped one of the two samples from the United States and the Singaporean sample because of missing responses. Because of problems with data collection, in these two samples the majority of participants did not provide responses to the item that asked about "lack of freedom". A total of 5,741 undergraduate university students completed the questionnaire. The mean age of the participants was 22.65 years $(S D=6.50)$ and $68 \%$ of the sample was female. Descriptive statistics of the samples in each country are shown in Table 1.

Table 1

Mean Scores on the Key Measure for Each National Sample $(N=5741)$

\begin{tabular}{|c|c|c|c|c|c|c|c|}
\hline Country & $N$ & $\begin{array}{c}\text { Female } \\
(\%)\end{array}$ & $\begin{array}{l}\text { Age } \\
(M)\end{array}$ & $\begin{array}{l}\text { Strong leader } \\
(M)\end{array}$ & $\begin{array}{l}\text { Mat. concerns } \\
\qquad(M)\end{array}$ & $\begin{array}{l}\text { Post-mat. concerns } \\
\text { (M) }\end{array}$ & $\begin{array}{l}\text { Mat. minus Post-mat. } \\
(M)\end{array}$ \\
\hline Australia & 149 & 71.8 & 22.17 & 5.64 & 8.20 & 8.57 & -0.37 \\
\hline Belgium & 242 & 22.1 & 20.37 & 4.64 & 13.82 & 10.29 & 3.53 \\
\hline Brazil & 146 & 63.2 & 23.99 & 5.29 & 21.81 & 15.33 & 6.48 \\
\hline Canada & 233 & 79.6 & 20.35 & 5.52 & 7.80 & 5.37 & 2.36 \\
\hline Chile & 151 & 33.3 & 20.64 & 4.52 & 11.79 & 7.38 & 4.41 \\
\hline China & 151 & 78.8 & 21.62 & 5.23 & 11.58 & 11.40 & 0.18 \\
\hline Denmark & 164 & 70.7 & 22.68 & 4.65 & 9.35 & 5.05 & 4.30 \\
\hline Finland & 113 & 77.0 & 25.58 & 4.54 & 6.40 & 5.89 & 0.51 \\
\hline France & 150 & 83.2 & 19.53 & 5.52 & 15.93 & 11.55 & 4.38 \\
\hline Germany $^{\mathrm{a}}$ & 322 & 70.2 & 22.05 & 3.77 & 9.39 & 9.04 & 0.38 \\
\hline Hungary & 160 & 40.3 & 24.75 & 5.13 & 19.17 & 12.74 & 6.43 \\
\hline India & 145 & 66.7 & 20.47 & 5.99 & 14.97 & 12.66 & 2.31 \\
\hline Indonesia & 557 & 77.4 & 21.42 & 6.31 & 21.46 & 14.92 & 6.54 \\
\hline Iran & 170 & 54.1 & 22.49 & 4.72 & 13.48 & 13.48 & 0.06 \\
\hline Italy & 156 & 67.8 & 25.87 & 5.00 & 18.74 & 11.85 & 6.88 \\
\hline Japan & 382 & 57.0 & 18.81 & 5.06 & 7.59 & 7.12 & 0.47 \\
\hline Latvia & 149 & 53.0 & 23.44 & 6.19 & 15.62 & 10.45 & 5.17 \\
\hline Malaysia & 112 & 84.8 & 23.20 & 6.37 & 18.05 & 15.42 & 2.63 \\
\hline Netherlands & 208 & 79.3 & 19.40 & 4.41 & 7.57 & 6.67 & 0.90 \\
\hline Pakistan $^{\mathrm{b}}$ & 150 & & 19.29 & 6.48 & 19.75 & 15.17 & 4.58 \\
\hline Poland & 180 & 73.4 & 27.72 & 4.94 & 14.35 & 9.85 & 4.50 \\
\hline Portugal & 160 & 71.1 & 22.24 & 5.62 & 19.69 & 9.58 & 10.11 \\
\hline South Africa & 451 & 81.4 & 21.10 & 6.37 & 18.81 & 12.20 & 6.61 \\
\hline Spain & 277 & 72.6 & 35.66 & 5.22 & 18.40 & 8.42 & 9.98 \\
\hline Switzerland & 448 & 64.2 & 24.13 & 3.58 & 7.39 & 6.97 & 0.42 \\
\hline UK & 74 & 83.6 & 21.11 & 5.55 & 10.57 & 7.75 & 2.82 \\
\hline US & 141 & 75.9 & 23.12 & 5.62 & 13.52 & 11.63 & 1.89 \\
\hline
\end{tabular}

${ }^{a}$ The two samples were aggregated. ${ }^{b}$ The survey in Pakistan did not specify the participant's gender.

3) Other articles using the same dataset have already been published; validating an anomie scale (Teymoori et al., 2016); examining the relation between in-group continuity and collective nostalgia (Smeekes et al., 2018), and a study on the relation between economic inequality on the desire for a strong leader (Sprong et al., 2019). 


\section{Individual-Level Measures}

\section{Materialist and Post-Materialist Concerns}

Participants were invited to answer the following question: "Next, please think about the life of the average (citizen of the country). What did the life of a/an (citizen of the country) look like during the last 30 days? Think about the conversations that this citizen of (this country) may have had, the things that they did, the people and situations that they encountered. What kind of problems could an average citizen of (this country) have encountered during the last 30 days?" Participants were asked to estimate how many days a citizen of their country encountered problems with or felt uncomfortable with the issue, indicating their responses ranging from 0 days to 30 days to a list of 25 problems or concerns.

In a first exploratory factor analysis (PCA), with the 25 items, we found four factors, the first of which explained most of the variance (see Table 5 in the Supplementary Materials). However, the factors were consistent with Inglehart's theory. Furthermore, some items were not applicable in all countries (i.e., immigration, overregulation, indecent or antisocial behavior), and others were theoretically irrelevant to Inglehart's (1971) theorizing about materialistic and post-materialist values (i.e., discrimination, alcohol or drug abuse, income inequalities, and quality of journalism). We therefore decided to remove these seven items from the analysis. After that, we performed a second PCA with the remaining 18 items (see Table 5.1 in the Supplementary Materials). We maintained only items with factor loadings above .50 for the composition of the dimensions of concern. This loading value was also adopted by Bean and Papadakis (1994) in their study to validate Inglehart's dimension values. Finally, the 15 items were submitted to a new PCA, as shown in Table 2.

\section{Table 2}

Loadings and Factors for Materialist and Post-Materialist Concerns in a Principal Components Using Oblimin Rotation

\begin{tabular}{|c|c|c|}
\hline Item & F1 & F2 \\
\hline Quality of politicians' work & .90 & -.16 \\
\hline The government & .84 & \\
\hline Quality of health care & .82 & \\
\hline Quality of education & .77 & \\
\hline Corruption or fraud & .76 & \\
\hline Unemployment & .72 & \\
\hline Quality of police work & .63 & .17 \\
\hline The economy & .60 & .18 \\
\hline Crime & .56 & .18 \\
\hline Selfishness or egotism & & .81 \\
\hline Privacy & -.12 & .80 \\
\hline Global warming and environment decline & & .64 \\
\hline Social cohesion & .17 & .58 \\
\hline Lack of respect & .27 & .56 \\
\hline Lack of freedom & .21 & .53 \\
\hline Eigenvalues & 7.16 & 1.27 \\
\hline Explained variance & 47.75 & 8.44 \\
\hline Cronbach's alpha & .91 & .81 \\
\hline
\end{tabular}

We believe that our process of elimination meant that we retained only those items that were relevant to capture materialistic and post-materialist values. The Kaiser-Meyer-Olkin (KMO) measure of sampling adequacy was acceptable (.94) and the Bartlett's test of sphericity was significant, $\chi^{2}(105)=41,459.44, p<.001$. The two factors were highly positively correlated, $r=.69, p<.001$. Closer inspection of the factor structure confirmed the two-factor structure proposed by 
Inglehart (1971): a set of items related to the prioritization of economic and physical security (i.e., materialist concerns), and the other factor included items that were concerned with self-expression and quality of life (i.e., post-materialist concerns). The reliability of the two dimensions was good: materialist concerns $\alpha=.91$ and post-materialist concerns $\alpha=.81$.

\section{Wish for a Strong Leader}

Our key dependent variable was measured with three items, where participants were asked to indicate their agreement with statements about the country's leadership: "Our country needs a strong leader right now", "We need strong leadership in order to make this society survive", and "We need strong leadership in order to overcome societies' difficulties". Participants indicated to what extent they agreed with the statements on a 7-point scale, ranging from 1 (strongly disagree) to 7 (strongly agree). A higher score denoted a stronger wish for a strong leader $(\alpha=.92)^{4}$.

\section{Country-Level Measures}

\section{Democracy Index 2014}

This index is compiled by the Economist Intelligence Unit, based on 60 indicators divided into five categories (electoral process and pluralism, civil liberties, functioning of government, political participation, and political culture). It assesses the level of democracy on a scale from 1 (authoritarian) to 10 (fully democratic). Scores in our sample ranged from 1.98 to 9.11 .

\section{Gross Domestic Product, Political Orientation, Gender and Age}

These variables were controlled in our analysis since they may covary in meaningful ways with our key variables. First, we analyzed the unique and controlled effect of Gross Domestic Product (GDP) because it is related to educational levels, and has been found to have an impact on post-materialist values (Inglehart \& Baker, 2000; Inglehart \& Welzel, 2005, 2012). GDP was captured as an index of monetary value of all goods and services produced within a country at purchasing power per capita in 2014. This measure assesses the total value produced in a country in a given year per citizen after equalizing the differences in price levels. GDP was measured in US dollars and divided by 10,000. Values ranged from 4.80 to 61.30 , with higher scores indicating higher levels of national wealth per capita.

Political orientation was measured using two items adapted from the European Social Survey, where participants were asked to place their views on social and economic issues on a left-wing/right-wing scale, ranging from 1 (strongly left) to 7 (strongly right). This variable was controlled for because individuals on the right of the political spectrum have been found to value authority more and thus value post-materialist concerns less (Altemeyer, 1998). The correlation between the two items assessing political orientation was moderately high and significant $(r=.60, p<.001)$ and the items were added together.

We also controlled for gender (female $=0$, male $=1$ ) and age, because these variables have been found to correlate with authoritarian attitudes and value acceptance (Inglehart, 2008; Inglehart \& Norris, 2017).

\section{Method of Analysis}

Since the data were collected in different countries, it is important to take the nested structure of the data into account. We estimated the multilevel models in SPSS mixed models and the cross-level mediating effect in Mplus (Version 8.3;

\footnotetext{
4) This measure has been used by Sprong and colleagues (2019, Study 1, based on the same database as our study). In Studies 2 and 3 , these authors included an extended measure of strong leadership. They added four new items to the original measure to more explicitly assess support for a leader who is willing to be more authoritarian and less democratic: "Australia needs a strong leader" followed by "who is willing to challenge democratic values and practices", "who is willing to break the rules", "who wants to change the status quo" and "who keeps tight control over the country's decisions and activities". The new scale had good internal reliability, $\alpha=.89$ and $\alpha=.85$, and importantly, its predictive power was largely the same when the longer or the shorter version was used. Additionally, convergent validation analysis of our measure was carried out using Vallerga's (2010) Pure Authoritarianism scale (PA). As shown in Table 6 (see Supplementary Materials), the correlation between our measure and PA was high and significant, $r(328)=.62, p<.001$, further confirming the validity of our scale (Techio, Torres, Pereira, de França, \& Lima, 2020).
} 
Muthén \& Muthén, 2012). The only variables with relatively large numbers of missing cases were political orientation (301, or 5.2\%), gender (285, or 5.0\%), and post-materialist concerns (277, or 4.8\%). In the cases of political orientation and gender, this occurred mainly because these questions were not included in Pakistan. For all other variables, the number of missing values did not constitute more than $3.6 \%$ of the sample. We used listwise deletion for these missing cases.

\section{Results}

\section{Descriptive Analysis}

Despite significant variation across countries (see Table 1), the overall levels of participants' wish for a strong leader was high and above the midpoint (4) of the scale, $M=5.22 ; S D=1.54, t(5724)=59.84, p<.001$. As can be seen in Table 1, the highest mean scores on the wish for a strong leader scale were found in Pakistan, Malaysia, South Africa, Indonesia and Latvia (above 6 on a 7-point scale).

The mean scores for both materialist and post-materialist concerns were relatively high: on average, participants estimated the average citizen was concerned with materialist concerns on 14 days per month, $M=14.00 ; S D=8.09$, and with post-materialist concerns on 10 to 11 days per month, $M=10.23 ; S D=6.73$. We subtracted post-materialist concerns from materialist (i.e., materialism minus post-materialism), and the mean was significantly different from zero, $M=3.70 ; S D=5.99, t(5431)=45.57 ; p<.001$, indicating more adherence to materialist than post-materialist concerns in the 27 countries. The largest gap between materialist and post-materialist concerns was found in Portugal, Spain, Italy, South Africa and Indonesia. In other words, in these countries, respondents perceived more concerns about the economy and crime than concerns relating to values of liberty and privacy. On the other hand, only among respondents from Australia were post-materialist concerns higher than materialist concerns.

\section{Main Analyses}

The control variables correlated with the main variables. At an individual-level, age correlated negatively with the wish for a strong leader, $r=-.07, p<.001$, and with left political orientation, $r=-.13, p<.001$. Younger participants expressed a higher wish for a strong leader and they were more right-wing oriented. Age was positively associated with materialist, $r=.09, p<.001$, and post-materialist concerns, $r=.03, p=.053$. Females reported a greater wish for a strong leader than males, $r=-.11, p<.001$. Right-wing political orientation was associated with a stronger wish for a strong leader, $r=.19, p<.001$, lower development of countries' democracy (country-level variable), $r=-.06, p<.001$, and lower GDP per capita (country-level variable), $r=-14, p<.001$.

In line with Inglehart' theorizing, there was a positive and significant correlation between materialist and post-materialist concerns, accounting for around 58 percent of their respective variances (see Table 3).

\section{Table 3}

Partial Inter-Correlations for Main Variables (Controlling Age, Sex and Political Orientation)

\begin{tabular}{|c|c|c|c|c|c|c|c|c|}
\hline Variable & Range & $M$ & $S D$ & 1 & 2 & 3 & 4 & 5 \\
\hline 1. Wish for a populist leader & $1-7$ & 5.22 & 1.54 & - & & & & \\
\hline 2. Materialist concerns & $0-30$ & 14.00 & 8.09 & $.30^{* * *}$ & - & & & \\
\hline 3. Post-materialist concerns & $0-30$ & 10.23 & 6.73 & $.18^{* * *}$ & $.69^{* * *}$ & - & & \\
\hline 4. Materialist - Post-materialist & $-20.9-26.4$ & 3.70 & 5.99 & $.21^{* * *}$ & $.58^{* * *}$ & $-.19^{* * *}$ & - & \\
\hline 5. Democracy Index & $1.98-9.11$ & 7.39 & 1.60 & $-.11^{* * *}$ & $-.20^{* * *}$ & $-.25^{* * *}$ & .01 & - \\
\hline 6. GDP & $10.6-61.3$ & 33.55 & 15.82 & $-.41^{* * *}$ & $-.49^{* * *}$ & $-.36^{* * *}$ & $-.26^{* * *}$ & $.56^{* * *}$ \\
\hline
\end{tabular}


The Democracy Index was negatively related with the wish for a strong leader. Consistent with our general hypothesis, the lower the level of democracy, the more participants expressed materialist concerns, and the more they expressed a wish for a strong leader. However, and somewhat inconsistent with Inglehart's theorizing, the Democracy Index was negatively related with post-materialist concerns and post-materialist concerns correlated positively with the wish for a strong leader.

To account for the nested nature of these relationships, we performed a multilevel analysis in two steps. First, we estimated the null model (i.e., the intercept-only model) to decompose the variances and obtain the intra-class correlation. A significant part of the variance in the wish for a strong leader $(I C C=.26)$, materialist concerns $(I C C=.37)$ and the post-materialist concerns $(I C C=.21$ ) was found between countries (see Table $4 \mathrm{a}$ and $4 \mathrm{~b}$ in the Supplementary Materials).

In a second step, we added the predictors to the model (see Table 4). Because of the high correlation between materialist and post-materialist concerns, we analyzed the effects of materialist and post-materialist concerns separately. In total, we tested five models, one including only the control variables (Model 1), another with both the control variables as well as both materialist and post-materialist concerns (Model 2), the third including only materialist concerns (Model 3), the fourth including only post-materialist concerns (Model 4), and, finally, the fifth using the difference score between materialist and post-materialist concerns (Model 5).

Table 4

Final Multilevel Model Predicting a Wish for a Strong Leader

\begin{tabular}{|c|c|c|c|c|c|c|c|c|c|c|}
\hline \multirow{3}{*}{$\begin{array}{l}\text { Multilevel models } \\
\text { predicting the wish for a } \\
\text { populist leader }\end{array}$} & \multicolumn{10}{|c|}{ Model } \\
\hline & \multicolumn{2}{|c|}{$\begin{array}{c}1 \text { - only control } \\
\text { variables }\end{array}$} & \multicolumn{2}{|c|}{2 - all variables } & \multicolumn{2}{|c|}{$\begin{array}{c}3 \text { - all variables } \\
\text { with materialist } \\
\text { concerns }\end{array}$} & \multicolumn{2}{|c|}{$\begin{array}{c}4 \text { - all variables } \\
\text { with post- } \\
\text { materialist } \\
\text { concerns }\end{array}$} & \multicolumn{2}{|c|}{$\begin{array}{c}5 \text { - all variables } \\
\text { and mat.-post. } \\
\text { concerns }\end{array}$} \\
\hline & $b$ & $S E$ & $b$ & $S E$ & $b$ & $S E$ & $b$ & $S E$ & $b$ & $S E$ \\
\hline Intercept & $4.69^{* * *}$ & 0.15 & $4.72^{* * *}$ & 0.15 & $4.72^{* * *}$ & 0.15 & $4.70^{* * *}$ & 0.15 & $4.72^{* * *}$ & 0.15 \\
\hline \multicolumn{11}{|l|}{ Individual level } \\
\hline Materialist concerns ${ }^{\mathrm{a}}$ & - & - & $0.18^{* * *}$ & 0.04 & $0.14^{* *}$ & 0.04 & - & - & - & - \\
\hline Post-materialist concerns ${ }^{a}$ & - & - & -0.05 & 0.03 & - & - & 0.04 & 0.02 & - & - \\
\hline Materialist - Postmat. ${ }^{a}$ & - & - & - & - & - & - & - & - & $0.10^{* *}$ & 0.02 \\
\hline Pol. orient. (right-wing) & $0.16^{* * *}$ & 0.01 & $0.15^{* * *}$ & 0.02 & $0.16^{* * *}$ & 0.02 & $0.16^{* * *}$ & 0.02 & $0.15^{* * *}$ & 0.01 \\
\hline Age & -0.00 & 0.00 & -0.00 & 0.00 & -0.00 & 0.00 & -0.00 & 0.00 & -0.00 & 0.00 \\
\hline Gender (male) & $-0.17^{* * *}$ & 0.04 & $-0.15^{* * *}$ & 0.04 & $-0.15^{* * *}$ & 0.04 & $-0.15^{* * *}$ & 0.04 & $-0.16^{* * *}$ & 0.04 \\
\hline \multicolumn{11}{|l|}{ Country level } \\
\hline $\mathrm{GDP}^{\mathrm{a}}$ & $-0.42^{* *}$ & 0.14 & $-0.50^{* *}$ & 0.16 & $-0.51^{* *}$ & 0.17 & $-0.59^{* *}$ & 0.17 & $-0.56^{* *}$ & 0.17 \\
\hline Democracy Index ${ }^{a}$ & - & - & 0.20 & 0.13 & 0.21 & 0.13 & 0.22 & 0.13 & 0.20 & 0.13 \\
\hline \multicolumn{11}{|l|}{ Variance components } \\
\hline Individual level & $1.59^{* *}$ & 0.03 & $1.58^{* * *}$ & 0.03 & $1.57^{* * *}$ & 0.03 & $1.59^{* * *}$ & 0.03 & $1.59^{* * *}$ & 0.03 \\
\hline Country level & $0.35^{*}$ & 0.10 & $0.29^{* *}$ & 0.09 & $0.30^{* *}$ & 0.09 & $0.30^{* *}$ & 0.09 & $0.30^{* *}$ & 0.09 \\
\hline \multicolumn{11}{|l|}{ Fit statistics } \\
\hline Log Likelihood (parameters) & \multicolumn{2}{|c|}{$17,191.50(7)$} & \multicolumn{2}{|c|}{$16,258.67(12)$} & \multicolumn{2}{|c|}{$16,812.02(10)$} & \multicolumn{2}{|c|}{$16,416.07(10)$} & \multicolumn{2}{|c|}{$16,282.15(10)$} \\
\hline AIC & \multicolumn{2}{|c|}{$17,205.50$} & \multicolumn{2}{|c|}{$16,282.67$} & \multicolumn{2}{|c|}{$16,832.02$} & \multicolumn{2}{|c|}{$16,436.07$} & \multicolumn{2}{|c|}{$16,302.15$} \\
\hline
\end{tabular}

${ }^{a}$ These variables (mat., post-mat., GDP and Democ. Index) were standardized prior to this analysis.

${ }^{*} p<.05 .{ }^{* *} p<.01 .{ }^{* * *} p<.001$.

Exploring Model 1, we found that right-wing political orientation, lower GDP and being female were all positively correlated with the wish for a strong leader. More importantly for our current purposes, over and above these control 
variables, the wish for a strong leader was predicted only by materialist, not by post-materialist concerns (Model 2). That is, when we took account of the shared variance between materialist and post-materialist concerns, post-materialist concerns no longer significantly predicted the wish for a strong leader $(p=.071)$ and was even negatively related to the wish for a strong leader. Interestingly too, the Democracy Index had no multilevel effect on the wish for a strong leader when the control variables as well as both materialist and post-materialist concerns were included in the model.

Model 3 tests the effect of materialist concerns only. It shows that materialist concerns continue to predict the wish for a strong leader when taking account of gender, GDP per capita and political orientation. Importantly, the Democracy Index is no longer significantly predicting wish for a strong leader when materialist concerns are taken into account, which suggests the possibility that the initial association between the Democracy Index and the wish for a strong leader is mediated $^{5}$ (see further below).

Replacing materialist concerns by post-materialist concerns (Model 4), post-materialist concerns did not significantly predict the wish for a strong leader. Finally, in Model 5, we replaced materialist and post-materialist concerns with the materialist and post-materialist difference score. This new variable has a positive relation with wish for a strong leader confirming Model 3 findings that the extent to which material concerns prevailed over post-materialist concerns predicted the wish for a strong leader.

\section{Mediation Model}

Given that only materialism and the difference score (i.e., materialism minus post-materialism) reliably predicted the wish for a strong leader, we conducted two mediational analyses, one including materialist concerns and another using the difference score between materialist and post-materialist concerns as the mediator. The mediations were tested as multilevel models in MPLUS Version 8.3 (Muthén \& Muthén, 2012). The model adopted was a 2-1-1, in which the predictor (Democracy Index) was included at the group-level, and the mediators (materialist or materialist minus post-materialist concerns) and the dependent variable (wish for a strong leader) were included as individual-level variables.

In line with our hypothesis, we found a significant indirect effect of democracy development via materialist concerns on the wish for a strong leader. As can be seen in Figure 1, the higher the Democracy Index, the less adherence to materialist concerns and the lower the wish for a strong leader. This suggests that the relation between the Democracy Index and the wish for a strong leader was mediated by materialist concerns (standardized indirect effect: - $.206,90 \%$ CI $[-.40,-.02])^{6}$. The adjusted $R^{2}$ of the final model was .37 , indicating that $37 \%$ of the wish for a strong leader was explained by these variables. The results show a specific type of mediation named indirect-only (Zhao et al., 2010), partially confirming our hypothesis?

The second multi-level mediational analysis testing the mediating power of the difference score between materialist and post-materialist concerns in the relation between democracy development and the wish for a strong leader did not reveal a significant standardized indirect effect: .10, 95\% CI $[-.05, .25]$. This suggests that this difference score did not mediate the relationship between the Democracy Index and the wish for a strong leader ${ }^{8}$.

\footnotetext{
5) Given that we use the same data set here as used by Sprong et al. (2019) demonstrating that economic inequality (as measured by the Gini coefficient) predicts the wish for a strong leader, we also explored whether this model still holds when controlling for economic inequality as measured by the Gini coefficient. In this model, we found that the effect of materialist concerns remains significant $(b=0.14, S E=0.04, p=.001)$ and the Gini coefficient was not significant $(b=0.15, S E=0.17, p=.414)$. The Akaike Information Criterion (AIC) of the Model 3 was lower than the AIC with the Gini coefficient (16,851.37), indicating Model 3 was a better fit to the data than a model that included the Gini coefficient.

6) Given the directionality of our hypotheses, we test the support using a one-tailed test.

7) We ran an additional model in which we used left-right political orientation as an additional mediator. The results indicated that mediation via materialism remains reliable (standardized indirect effect: $-.202,90 \%$ CI [-.39, -.02]) even after taking into account the mediating role of left-right, which is not reliable (standardized indirect effect: $-.085,90 \%$ CI $[-.23, .06]$.

8) This situation remains unchanged even after controlling for the mediation via the left right, which is also not significant in this analysis (standardized indirect effect: $-.098,90 \%$ CI $[-.26, .06]$.
} 


\section{Figure 1}

Hierarchical Linear Modelling to Examine the Relation of Democracy Index on Wish for a Strong Leader Mediated by the Materialist Concerns

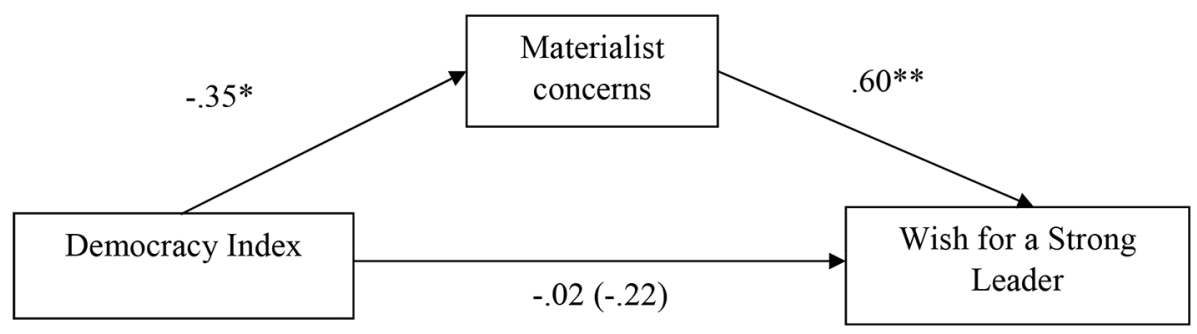

${ }^{*} p<.05 .{ }^{* *} p<.01$.

\section{Discussion}

The purpose of this study was to understand the extent to which low levels of democracy are associated with concerns about materialist needs and whether, in turn, this is associated with the wish for a strong leader. Specifically, we predicted that materialist concerns, challenging the satisfaction of the most immediate and basic needs and values, would mediate the relation between democracy development and the wish for a strong leader in a sample of individuals from 27 countries. Our findings partially confirm our hypothesis. We draw four general conclusions.

First, we found that lower democracy development at the national level was related to more support for a strong leader, suggesting that the weakness of democratic institutions gives rise to populist leaders (Daly, 2018). This finding is in line with research that has shown that regions with the largest declines in the Democracy Index in 2014 (Latin America, Middle East and North Africa, and Sub-Saharan Africa) were also those with the most popular discontent with democracy and greater electoral success of populist parties (EIU, 2014). As political scientists have asserted, populism constitutes an ideological critique of the shortcomings of the democratic order, legitimizing proposals to achieve desired ends for people, even when that means disrespecting rules of the democratic game (Crouch, 2019; Landau, 2018).

Second, our results suggest that to understand the relation between democracy development and support for a strong leader, it is instructive to consider the role of materialist concerns. These results confirm Inglehart's theses about the importance of materialist values in predicting populist political choices (Inglehart \& Baker, 2000; Inglehart \& Welzel, 2012). That is, even in the post-industrial countries and among younger and more educated people (our data comprised of college student samples) materialist concerns were found to play a central role in the preference for stronger leaders. This result also corroborates data from other studies, using representative samples, which show that adherence to materialist values is related to non-democratic attitudes around the world (e.g., Inglehart, 2016; Inglehart, 2018; Inglehart \& Norris, 2017).

Third, we also found that the relationship between the Democracy Index and the wish for a strong leader changed markedly when controlling for GDP per capita. When we introduced GDP per capita into multi-level analysis, post-materialist values and the Democracy Index no longer predicted the wish for a strong leader. This suggests that the effects of democratization and economic growth are closely aligned and intimately connected (see also Inglehart \& Welzel, 2012).

Finally, and most importantly, our results demonstrate that materialist concerns do mediate the effect of democracy development on the wish for a strong leader. This mediational effect was stronger when we did not control for GDP per capita but still holds when controlling for GDP (albeit only significantly so when we relaxed our analysis to a one-tailed test). This provides some evidence that the lack of democracy consolidation is related to the most basic concerns of life in society, fueling the demand for political leaders who can overcome this situation, often regardless of the means they will use. These results are in line with theories that affirm that values play a central role connecting culture to individuals (Cooper \& Denner, 1998). In this study, political culture, represented by the countries' Democracy Index, was associated of individual choices or attitudes, specifically the wish for strong leaders, through materialist concerns. The results also confirm those of Inglehart's values model (Inglehart, 1971, 2000, 2008, 2018; Inglehart \& Baker, 2000; 
Inglehart \& Norris, 2017; Inglehart \& Welzel, 2005, 2012) and go beyond them by demonstrating, with data from 27 countries with different levels of democracy consolidation and diverse political cultures, that materialist values play a mediational role in the relation between democracy and individual political choices.

\section{Limitations and Future Directions}

Notwithstanding the contributions to the understanding of the interplay of democracy, materialist concerns and wish for a strong leader, at least three limitations of this research must be mentioned. First, our measure of "wish for a strong leader" was rather brief and, arguably, did not explicitly assess support for a strong and non-democratic leader. Nevertheless, there is evidence in the work by Sprong and colleagues (2019) and Techio and colleagues (2020) that the three items used in our study were related to key predictors of more extensive scales that better tap support for a populist and authoritarian leader (see Footnote 4). Second, given that our data were cross-sectional and not longitudinal, we are not in a position to comment on how declining or improving democracy levels over time predict support for a strong leader. To explore these processes, it would be important to collect longitudinal data that would allow for the study of the process of democracies' erosion over time and its effect on materialist and post-materialist values as well as support for populist leaders. Third, our sample in each country was small and in particular, as it was made up of university students, was restricted to a WEIRD cultural niche (Henrich et al., 2010). Moreover, as Van Assche and colleagues (2018) demonstrate, the "liberalizing" effect of education is stronger in Western countries high in the Human Development Index. As a result, because our sample consisted mostly of university students, we may have potentially overestimated the 'true' post-materialist values in these Western countries. To strengthen the external validity of the findings, in future research, it would be important to explore the relationship between key variables in representative samples.

\section{Conclusion}

The current research demonstrates that the relationship between some countries' low democracy development and the wish for a strong leader is related to concerns around materialist value satisfaction. This finding sits well with recent work in the political sciences that suggests that political changes, (e.g., the election of an authoritarian leader in countries with consolidated or consolidating democracy) can be due to disruptive variation in democratic institutions. The change in values that challenges democratic systems has been described as a slow and invisible ("glacial") change - a change however that may affect the social and political field in profound ways (Welzel, Inglehart, \& Kruse, 2017). Although the focus has so far been on the effects of strengthening of democracy, retractions from democracy can also happen (e.g., when the popular demand for freedoms is superseded by other needs). This then provides a fertile ground for authoritarian leaders who find little resistance to imposing restrictions on freedoms.

The work presented here is important because although there is a strong consensus in social psychology that values form a bridge between individual and societal variables, the functioning and development of democratic institutions as a system is closely linked with individual-level variables. As far as we know, there has been no research yet which has tested the mediational role of materialist and post-materialist concerns in the relationship between the strength of democracy and the wish for strong leaders. Our results suggest that, in contexts where materialist concerns become more salient, supporters of democracy must be more alert to the appeal of populist and authoritarian leaders.

Funding: This contribution was supported by an Australian Research Council Discovery Grant (DP170101008), Center for Social Conflict and Cohesion Studies (ANID/FONDAP \#15130009) and the Center for Intercultural and Indigenous Research (ANID/FONDAP \#15110006). This contribution was supported too by the Brazilian Research Council (CNPq - 204632/2018-8)

Acknowledgments: The authors have no additional (i.e., non-financial) support to report.

Competing Interests: The authors have declared that no competing interests exist. 


\section{Supplementary Materials}

The Supplementary Materials include tests of the null model (Tables 4a and 4b), the initial factor analysis of the materialistic and post-materialist values scale (Tables 5 and 5.1), and the convergent validation of the strong leader measure with an authoritarian scale (Table 6) (for access see Index of Supplementary Materials below).

\section{Index of Supplementary Materials}

Lima, M. E. O., de França, D. X., Jetten, J., Pereira, C. R., Wohl, M. J. A., Jasinskaja-Lahti, I., . . van der Bles, A. M. (2021). Supplementary materials to "Materialist and post-materialist concerns and the wish for a strong leader in 27 countries" [Additional information]. PsychOpen GOLD. https://doi.org/10.23668/psycharchives.4802

\section{References}

Abramson, P. R., \& Inglehart, R. (1987). Generational replacement and the future of post-materialist values. The fournal of Politics, 49, 231-241. https://doi.org/10.2307/2131142

Altemeyer, B. (1998). The other "authoritarian personality." Advances in Experimental Social Psychology, 30, 47-92. https://doi.org/10.1016/S0065-2601(08)60382-2

Bean, C., \& Papadakis, E. (1994). Polarized priorities or flexible alternatives? Dimensionality in the Materialism-Postmaterialism Scale. International fournal of Public Opinion Research, 6(3), 264-288. https://doi.org/10.1093/ijpor/6.3.264

Cooper, C. R., \& Denner, J. (1998). Theories linking culture and psychology: Universal and community-specific processes. Annual Review of Psychology, 49, 559-584. https://doi.org/10.1146/annurev.psych.49.1.559

Crouch, C. (2019). Post-democracy and populism. The Political Quarterly, 90, 124-137. https://doi.org/10.1111/1467-923X.12575

Daly, T. G. (2018, June). Populism, elitism and democratic decay in Brazil. Paper presented at the Annual Conference of the International Society of Public Law (I-CON S), Hong Kong, 26 June, Panel: Populist Challenges to Liberal Constitutionalism II. Retrieved from https://www.academia.edu/36908169/Populism_Élitism_and_Democratic_Decay_in_Brazil

Davis, D. W., \& Davenport, C. (1999). Assessing the validity of the post-materialism index. American Political Science Review, 93, 649-664. https://doi.org/10.2307/2585580

Economist Intelligence Unit. (2014). Democracy Index 2014: Democracy and its discontents. Retrieved from https://www.sudestada.com.uy/Content/Articles/421a313a-d58f-462e-9b24-2504a37f6b56/Democracy-index-2014.pdf

Economist Intelligence Unit. (2019). Democracy Index 2019: A year of democratic setbacks and popular protest. Retrieved from https:/www.in.gr/wp-content/uploads/2020/01/Democracy-Index-2019.pdf

Hadler, M. (2012). The influence of world societal forces on social tolerance: A time comparative study of prejudices in 32 countries. The Sociological Quarterly, 53, 211-237. https://doi.org/10.1111/j.1533-8525.2012.01232.x

Henrich, J., Heine, S. J., \& Norenzayan, A. (2010). The weirdest people in the world? Behavioral and Brain Sciences, 33(2-3), 61-83. https://doi.org/10.1017/S0140525X0999152X

Inglehart, R. (1971). The silent revolution in Europe: Intergenerational change in post-industrial societies. American Political Science Review, 65, 991-1017. https://doi.org/10.2307/1953494

Inglehart, R. (2000). Globalization and postmodern values. The Washington Quarterly, 23, 215-228. https://doi.org/10.1162/016366000560665

Inglehart, R. (2008). Changing values among western publics from 1970 to 2006. West European Politics, 31, 130-146. https://doi.org/10.1080/01402380701834747

Inglehart, R. (2016). After post-materialism: An essay on China, Russia and the United States: A comment. Canadian fournal of Sociology, 41(2), 213-222. https://doi.org/10.29173/cjs27993

Inglehart, R. (2018, May-June). The age of the insecurity: Can democracy save itself? Foreign Affairs, 97(3), Article 2. Retrieved from https://www.foreignaffairs.com/articles/2018-04-16/age-insecurity

Inglehart, R., \& Abramson, P. R. (1999). Measuring post-materialism. American Political Science Review, 93, 665-677. https://doi.org/10.2307/2585581 
Inglehart, R., \& Baker, W. E. (2000). Modernization, cultural change, and the persistence of traditional values. American Sociological Review, 65, 19-51. https://doi.org/10.2307/2657288

Inglehart, R., \& Norris, P. (2016). Trump, Brexit, and the rise of populism: Economic have-nots and cultural backlash (HKS Faculty Research Working Paper No. RWP16-026). https://doi.org/10.2139/ssrn.2818659

Inglehart, R., \& Norris, P. (2017). Trump and the populist authoritarian parties: The silent revolution in reverse. Perspectives on Politics, 15(2), 443-454. https://doi.org/10.1017/S1537592717000111

Inglehart, R., \& Welzel, C. (2005). Modernization, cultural change, and democracy: The human development sequence. Cambridge, United Kingdom: Cambridge University Press.

Inglehart, R., \& Welzel, C. (2012). How development leads to democracy: What we know about modernization. Foreign Affairs, 88(2), 33-48. Retrieved from https://www.jstor.org/stable/20699492

Kaase, M., \& Newton, K. (1995). Beliefs in government. Oxford, United Kingdom: Oxford University Press.

Landau, D. (2018). Populist constitutions. University of Chicago Law Review, 85, 521-543. Retrieved from https://ssrn.com/abstract=3053513

Muthén, L. K., \& Muthén, B. O. (2012). Mplus user's guide: Statistical analysis with latent variables (7th ed). Los Angeles, CA, USA: Muthén \& Muthén.

Norris, P. (2017a). Why American elections are flawed (and how to fix them). Ithaca, NY, USA: Cornell University Press.

Norris, P. (2017b). Is western democracy backsliding? Diagnosing the risks (HKS Working Paper No. RWP17-012). https://doi.org/10.2139/ssrn.2933655

Smeekes, A., Jetten, J., Verkuyten, M., Wohl, M. J. A., Jasinskaja-Lahti, I., Ariyanto, A., . . van der Bles, A. M. (2018). Regaining ingroup continuity in times of anxiety about the group's future: A study on the role of collective nostalgia across 27 countries. Social Psychology, 49, 311-329. https://doi.org/10.1027/1864-9335/a000350

Sortheix, F. M., \& Schwartz, S. H. (2017). Values that underlie and undermine well-being: Variability across countries. European fournal of Personality, 31(2), 187-201. https://doi.org/10.1002/per.2096

Sprong, S., Jetten, J., Wang, Z., Peters, K., Mols, F., Verkuyten, M., . . Wohl, M. J. A. (2019). “Our country needs a strong leader right now”: Economic inequality enhances the wish for a strong leader. Psychological Science, 30(11), 1625-1637.

https://doi.org/10.1177/0956797619875472

Techio, E. M., Torres, A. R. R., Pereira, C. R., de França, D. X., \& Lima, M. E. O. (2020). Authoritarianism and political choice in Brazil. Unpublished manuscript.

Teymoori, A., Jetten, J., Bastian, B., Ariyanto, A., Autin, F., Ayub, N., .. Wohl, M. (2016). Revisiting the measurement of anomie. PLoS One, 11(7), Article e0158370. https://doi.org/10.1371/journal.pone.0158370

Vallerga, M. E. (2010). Pure authoritarianism: A new approach to authoritarianism (Master's thesis, San José State University, San José, CA, USA). Retrieved from http://scholarworks.sjsu.edu/etd_theses/3897

Van Assche, J., Dhont, K., Van Hiel, A., \& Roets, A. (2018). Ethnic diversity and support for populist parties: The "right" road through political cynicism and lack of trust. Social Psychology, 49(3), 182-189. https://doi.org/10.1027/1864-9335/a000340

Welzel, C., Inglehart, R., \& Kruse, S. (2017). Pitfalls in the study of democratization: Testing the emancipatory theory of democracy. British fournal of Political Science, 47(2), 463-472. https://doi.org/10.1017/S0007123415000605

Zhao, X., Lynch, J. G., Jr., \& Chen, Q. (2010). Reconsidering Baron and Kenny: Myths and truths about mediation analysis. Journal of Consumer Research, 37, 197-206. https://doi.org/10.1086/651257 